\title{
LASER AND LASER-MICROPLASMA ALLOYING OF SURFACE OF 38KhN3MFA STEEL SPECIMENS
}

\author{
V.D. SHELYAGIN, L.I. MARKASHOVA, V.Yu. KHASKIN, A.V. BERNATSKY and O.S. KUSHNARYOVA \\ E.O. Paton Electric Welding Institute, NASU \\ 11 Bozhenko Str., 03680, Kiev, Ukraine. E-mail: office@paton.kiev.ua
}

\begin{abstract}
Considered are the technologies of laser and laser-microplasma alloying of surface layers of 38KhN3MFA structural steel specimens with introduction of powder filler materials based on tungsten and chromium carbide, promoting increase of physical-chemical properties of the parts, manufactured from these steels. Structural transformations, concentration variations and reasons of crack formation in treated surface layers were investigated at different modes of alloying using the methods of light microscopy and analytic scanning electron microscopy. It is shown that susceptibility to crack formation in laser and laser-microplasma alloying of specimens of 38KhN3MFA steel is caused, first of all, by structural (size of crystalline particles, coefficient of their shape) and concentration variations, related with redistribution of the elements, in particular, chromium, that results in formation of grain boundary concentration gradients. Absence of microcracks in a fusion zone at laser-microplasma method of alloying allows making a conclusion about perspective of application of this method for surface treatment of parts, manufactured from 38KhN3MFA steel. 6 Ref., 9 Figures.
\end{abstract}

Key words: structural steel, treated surfaces, laser alloying, structure

General tendencies for development of current machine building lie in intensifying of the production processes due to increase of main technological parameters (temperature, pressure, concentration of reacting substances, etc.). This provides for a rise of requirements to safe operation of equipment, mechanisms and machines. Constant reduction of weight and dimensions of mechanisms and increase of their power result in rise of loads and stresses in the parts, that, in turn, require development and shifting to new, safer structural materials.

Today, bulk alloying of steels becomes uneconomical due to large consumption of expensive materials [1]. However, level of service properties of the unalloyed steels is not sufficient for their application in current industry. One of the solutions is an application of surface alloying of steels and alloys, that allows receiving the necessary surface properties at minimum consumption of alloying elements.

Most of the traditional methods of surface alloying are based, as a rule, on the processes of diffusion saturation with elements from gaseous or liquid phase in combination with heat (chemical-heat) treatment [2]. However, application of traditionally used chemical-heat or bulk heat treatment is not sufficient in number of cases for receiving of set level of service properties.
Therefore, the development of surface engineering at present stage, considering the problems related with strengthening technologies applied now, assumes creation of new level technological processes allowing modification of a surface layer, changing of its structure and properties [3]. At that, the preference during modification of metal surfaces is given to the methods of strengthening treatment using as a heat source the concentrated energy flows, namely ion, laser, ultrasonic, electron beam and others.

Considering the fact that laser technologies allow successfully solving a problem of development of materials with set complex of properties by means of directed formation of necessary structure along the whole volume of metal, there is a possibility in application of laser treatment for strengthening of local volumes, in particular, surface layers of treated material. Application of such an approach of laser alloying develops the possibility for formation of surfaces characterizing by high level of hardness, heat, wear and corrosion resistance. Thus, present work is dedicated to the investigation of surface alloying of steel and surface structures being formed under different conditions of irradiation in order to optimize the technological modes of laser alloying.

Materials and methods of investigation. Laser and laser-microplasma surface alloying of end face of circular specimens from 38KhN3MFA structural steel were carried out in course of investigations. Chemical composition of 


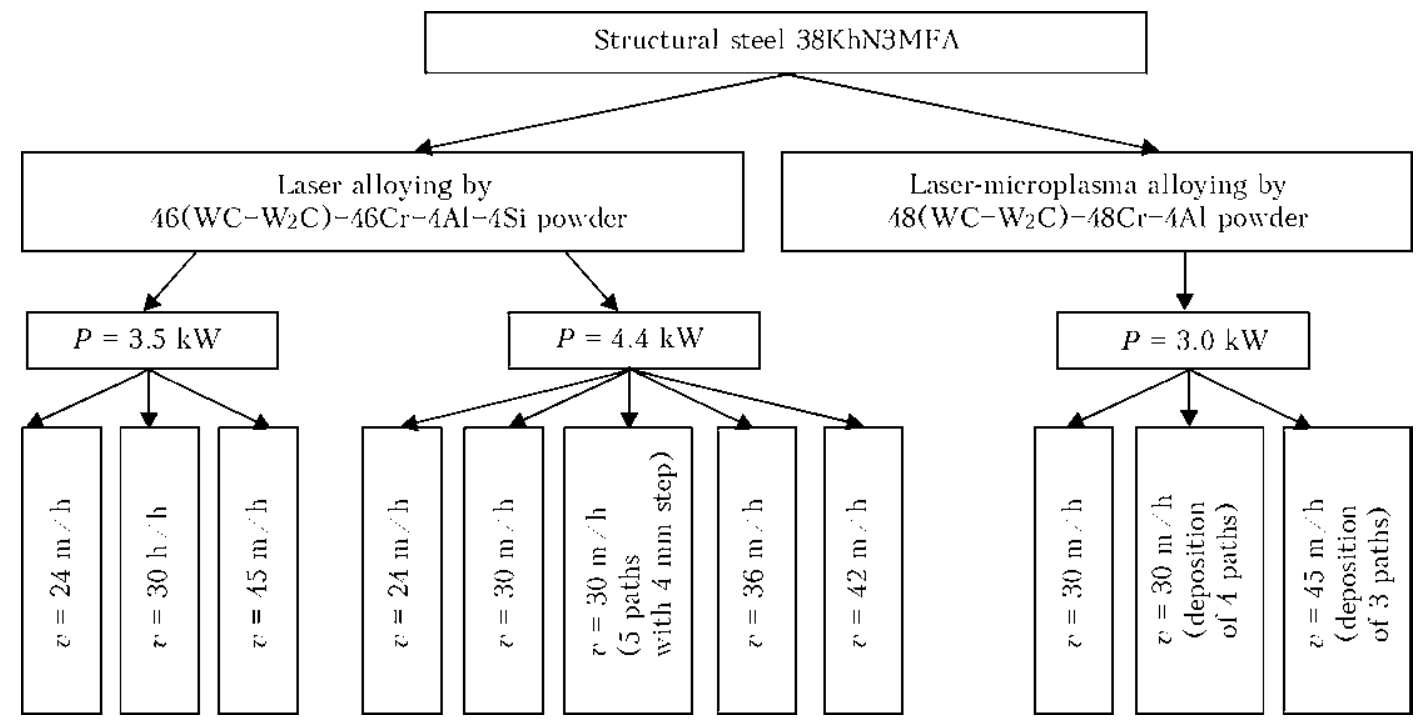

Figure 1. Flow-chart of investigated specimens

38KhN3MFA steel (GOST 4543-71) is as follows, wt.\%: $0.33-0.40 \mathrm{C}$; $0.17-0.37 \mathrm{Si} ; 0.25-$ $0.50 \mathrm{Mn} ; 3.0-3.5 \mathrm{Ni} ; 1.2-1.5 \mathrm{Cr} ; 0.35-0.45 \mathrm{Mo}$; $0.10-0.18 \mathrm{~V} ;<0.3 \mathrm{Cu} ;<0.025 \mathrm{~S} ;<0.025 \mathrm{P}$.

Mechanical properties of $38 \mathrm{KhN} 3 \mathrm{MFA}$ steel at $T=20{ }^{\circ} \mathrm{C}(\operatorname{rod}$ diameter $25 \mathrm{~mm})$ are $\sigma_{\mathrm{t}}=$ $=1180 \mathrm{MPa} ; \sigma_{0.2}=1080 \mathrm{MPa} ; \delta=12 \% ; \psi=$ $=50 \% ; K C U=780 \mathrm{~kJ} / \mathrm{m}^{2}$. Mechanical mixture of $0-40 \mu \mathrm{m}$ fraction powders of the following composition, wt.\%: $46\left(\mathrm{WC}-\mathrm{W}_{2} \mathrm{C}\right)+46 \mathrm{Cr}+$ $+4 \mathrm{Al}+4 \mathrm{Si}$, was used in laser alloying, and $48\left(\mathrm{WC}-\mathrm{W}_{2} \mathrm{C}\right)+48 \mathrm{Cr}+4 \mathrm{Al}$ composition was applied in laser-microplasma alloying.

ROFIN-SINAR Nd:YAG-laser DY044 (Germany) with irradiation wave length $\lambda=1.06 \mu \mathrm{m}$ was used for laser alloying. Equipment and technologies of laser-plasma alloying were developed at the E.O. Paton Electric Welding Institute. A laboratory bench was assembled on the basis of three-coordinated manipulator «Lastochka-1».

Laser irradiation was transferred using optic fiber of $600 \mu \mathrm{m}$ diameter and $20 \mathrm{~m}$ length manufactured from quartz glass. The laser irradiation from optic fiber came to a collimator, where it was transformed with the help of the system of optical elements and received the necessary geometry, and then was transmitted to focusing quartz lens of $50 \mathrm{~mm}$ diameter with focal distance $F=200 \mathrm{~mm}$. Treatment was carried out with variation of laser irradiation power in $P=3.0$ $4.4 \mathrm{~kW}$ limits, treatment speed $v=24-45 \mathrm{~m} / \mathrm{h}$ and value of irradiation defocusing $\Delta F=30$ $45 \mathrm{~mm}$. More detailed state of the investigated specimens is represented in a flow diagram ( $\mathrm{Fi}^{-}$ gure 1).

The experiments on laser alloying were carried out on scheme given in work [4]. At that, stationary specimen was located on object table and laser head was fixed on movable carriage of the manipulator. Structure of laser head allowed performing treatment of the specimen with axial feed of laser irradiation and filler powder mixture. The latter was transported in a nozzle part of the head using argon and dosing at that was carried out by vibrating feeder of the E.O. Paton Electric Welding Institute production. The laser head was fixed at $10^{\circ}$ angle to vertical axis in order to prevent entering of irradiation reflected from surface of melt pool into optical path.

The laser head and microplasmatron were based on a stationary support during performance of the experiments on laser-microplasma alloying. The specimens were fixed in the clamps positioned on movable carriage of the three-coordinated manipulator (Figure 2). End face of the specimen in form of ring was linearly alloyed at longitudinal movement of the carriage. At that, the melt pool of up to $2 \mathrm{~mm}$ depth was formed on the specimen surface. Mechanical mixture of

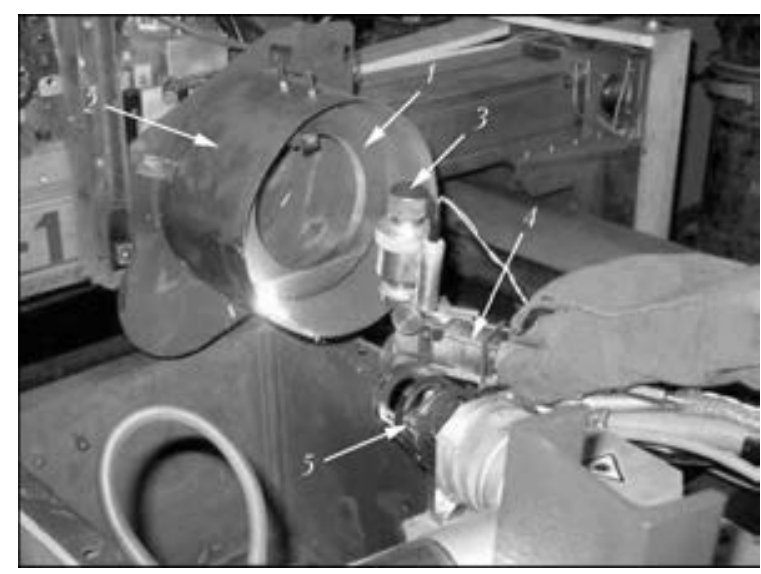

Figure 2. Bench for surface laser-microplasma alloying: 1 specimen fixed in clams; 2 - protective cover; 3 - powder measuring hopper; 4 - microplasmatron; 5 - laser focusing head 
powders was fed in it by a jet of laminar argon plasma. Power supply of the plasmatron was carried out using MPU-4 power source at 40-50 A current and around $32 \mathrm{~V}$ voltage. The distance from microplasmatron nozzle to treatment zone made 12-150 $\mathrm{mm}$. Convergence angle of axes of laser irradiation and mictroplasma jet made $30-45^{\circ}$.

Metallographic investigations for determination of general dependence of formation of surface structure in alloyed layers, received by different methods (laser and laser-microplasma alloying), were carried out by light microscopy method on Versamet-2. Content of elements in solid solution and in separate inclusions was investigated using analytical scanning microscopy method on Philips SEM-515 unit (Holland).

Nature of laser alloying effect. Carried investigations of process of laser alloying showed that active local heating of filler material, promoting formation of vapor-gas phase over liquid phase surface (melt pool), takes place at power irradiation densities of $10^{5}-10^{6} \mathrm{~W} / \mathrm{cm}^{2}$. At that, the latter includes the turbulent flows resulting in mixing of base and filler materials [4]. Besides, movement of laser beam results in difference of surface tension forces in central and tail parts of the melt pool. That in combination with effect of vapor pressure and turbulent flows of the melt promotes relatively uniform distribution of filler material through the whole depth of melt pool and formation of alloyed layer.

Increase of power density of laser irradiation above $10^{6} \mathrm{~W} / \mathrm{cm}^{2}$ leads to shifting in a keyhole penetration mode, characterized by formation vapor-gas channel in the melt pool [4,5]. The latter results in such unfavorable effects as burning out of chemical elements of filler material, formation of pores and cavities (due to collapse of vapor-gas pockets on the surface, with formation of wormholes inside the treated layer due to small time of liquid phase existence), increase of HAZ and transfer zone, slopping of base metal into the alloyed layer. Thus, for elimination of indicated defects, the power density of irradiation in a heating spot was limited approximately to (810) $\cdot 10^{5} \mathrm{~W} / \mathrm{cm}^{2}$ during performance of the experiments.

Reduction of power density of irradiation below $(2-4) \cdot 10^{4} \mathrm{~W} / \mathrm{cm}^{2}$ resulted in absence of uniformly remelted layer of metal.

Investigations of structure. The metallographic investigations were carried out in different areas, namely alloyed layer $\rightarrow$ fusion zone $\rightarrow$ base metal of each of 11 specimens (differ by parameters of technological modes).

Laser treatment of the surface was performed with $P=3.5 \mathrm{~kW}$ power at different alloying speed $v=24-45 \mathrm{~m} / \mathrm{h}$ as well as with increased power up to $4.4 \mathrm{~kW}$ at $v=24-42 \mathrm{~m} / \mathrm{h}$. Lasermicroplasma treatment was carried out with constant power $P=3 \mathrm{~kW}$ and varying alloying speed (it was changed from 30 to $45 \mathrm{~m} / \mathrm{h}$ ) at deposition of different number of paths.

Laser alloying. It was determined that thickness of surface alloyed layer changed from 1.55 to $2.10 \mathrm{~mm}$ in laser alloying (with $P=3.5$ as well as $4.4 \mathrm{~kW}$ ) at increase of alloying speed $(v=24,30,45 \mathrm{~m} / \mathrm{h})$. Metal of the surface alloyed layer has a well-defined structure of elongated shape $(h \times l)$ of crystalline particles (where $h$ is the width, and $l$ is the crystalline particle elongation), size of which on average make $h \times$ $\times l=15 \times 85 \mu \mathrm{m}$ at $v=24 \mathrm{~m} / \mathrm{h}, 20 \times 80 \mu \mathrm{m}$ for $v=30 \mathrm{~m} / \mathrm{h}$ and $15 \times 100 \mu \mathrm{m}$ with $v=45 \mathrm{~m} / \mathrm{h}$ (Figure 3, $a$ ). Thus, change of shape coefficients $\kappa$ of crystalline particles is observed [6], the values of which on average are 5 for $24 \mathrm{~m} / \mathrm{h}, 3$ for $30 \mathrm{~m} / \mathrm{h}$, and it rises up to 6 with increase of speed of laser alloying to $45 \mathrm{~m} / \mathrm{h}$. Increase of microhardness in the alloyed layer on average by $30-36 \%$ was also registered depending on rise of speed from 24 to $45 \mathrm{~m} / \mathrm{h}$ at $P=3.5 \mathrm{~kW}$.

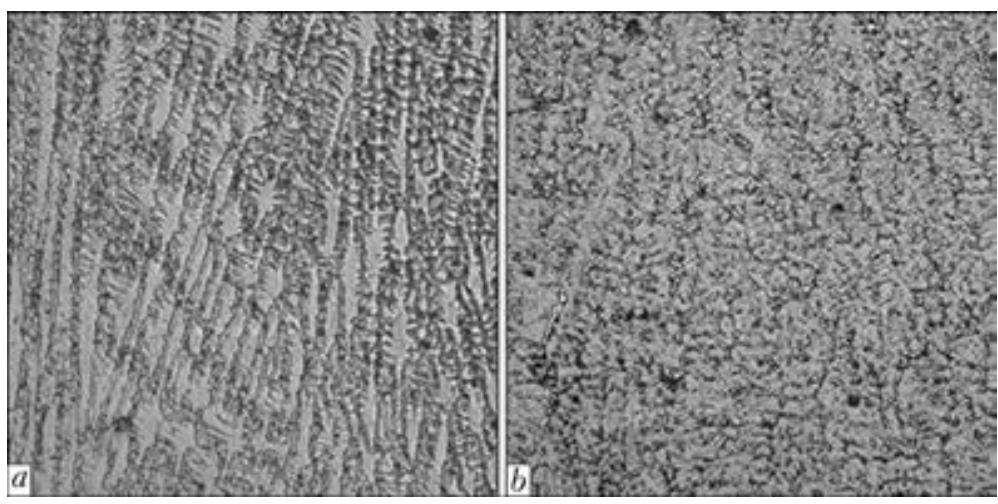

Figure 3. Microstructure $(\times 500)$ of surface layers of structural steel 38KhN3MFA under conditions of laser $(a)$ and laser-microplasma $(b)$ alloying 


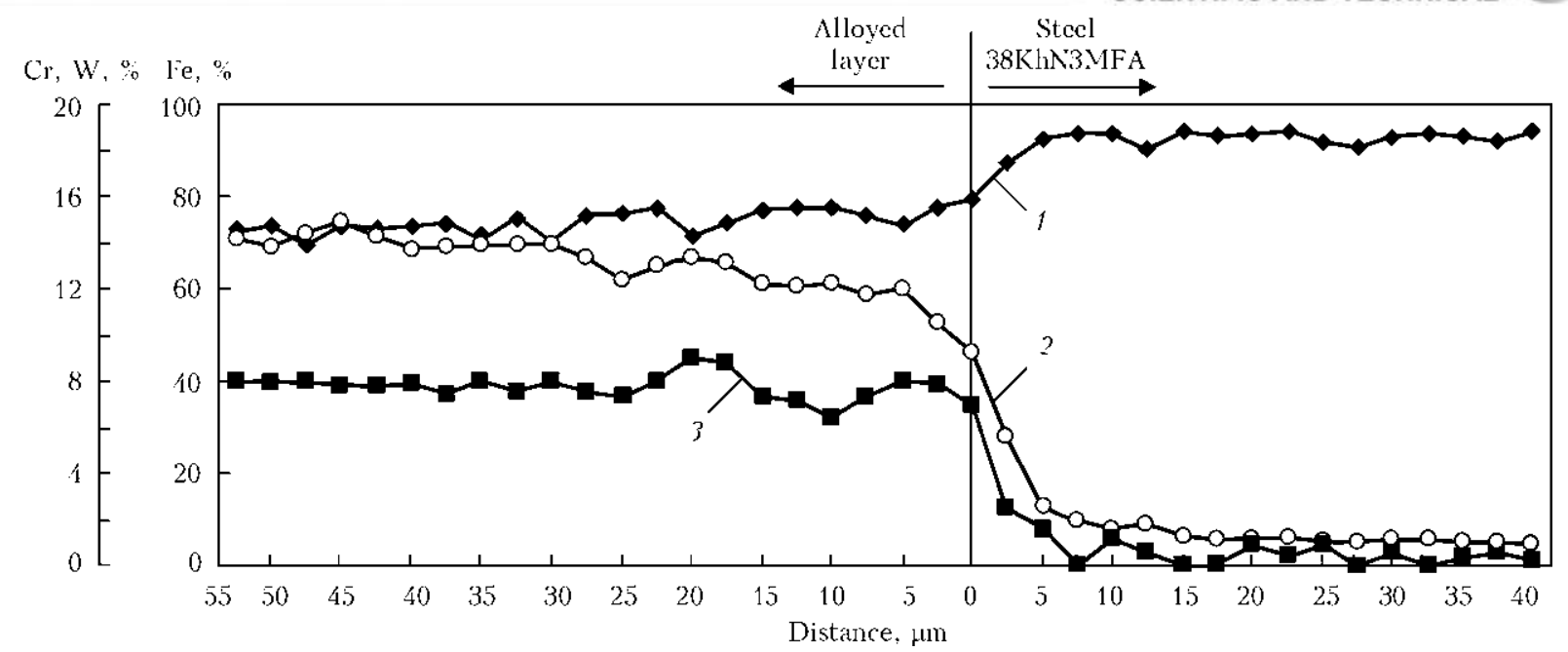

Figure 4. Concentration variations of iron (1), chromium (2) and tungsten (3) from outer surface of alloyed layer to base metal 38KhN3MFA after laser alloying at $P=3.5 \mathrm{~kW}$ and $v=30 \mathrm{~m} / \mathrm{h}$

HAZ is observed from the side of $38 \mathrm{KhN} 3 \mathrm{MFA}$ base metal directly near the fusion line. The width of the latter rises from 1.30 to $1.65 \mathrm{~mm}$ with increase of microhardness in this zone at alloying speed rise from 24 to $45 \mathrm{~m} / \mathrm{h}$, respectively. It should be noted, in this case, that the structural mixture of sorbite and martensite is observed in the base metal, whereas HAZ metal has martensite structure for all considered cases of alloying speed. Besides, concentration variations in the treated surfaces were investigated and showed that the most uniform saturation of the surface layer by alloying elements is noted with $v=$ $=30 \mathrm{~m} / \mathrm{h}$ and $P=3.5 \mathrm{~kW}$. In this case, concentration of elements makes, wt.\%: 70-75 Fe, 12$14 \mathrm{Cr}, 7-8 \mathrm{~W}$, without rapid gradient of concentration variations in a transfer zone (extension of which does not exceed $25 \mu \mathrm{m}$ ) from the fusion line in a direction of outer surface of alloyed layer (Figure 4).

Investigations of nature of inclusions in the treated surfaces were carried in addition to the investigations of concentration variations. It is shown that coarse inclusions (Figure 5) in the amount of up to $1 \%$ and $25 \mu \mathrm{m}$ size are observed in the case of laser alloying of surface layer at

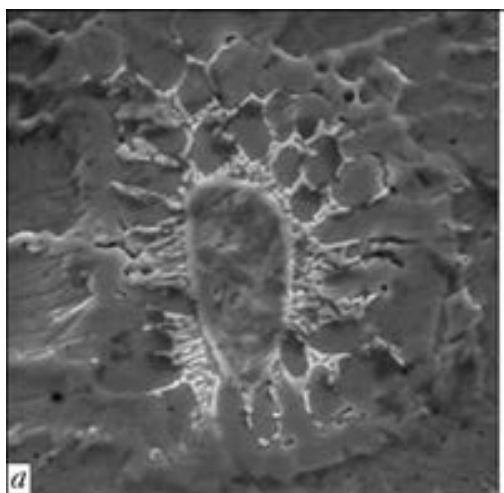

all alloying speeds. These inclusions differ by high content of tungsten (up to 95-97\%), and, obviously, being the $\mathrm{WC}-\mathrm{W}_{2} \mathrm{C}$ particles not dissolved during the alloying process.

The next stage of work was directed on investigation of presence and nature of cracks, zones of their distribution in the surface layers at $P=$ $=3.5 \mathrm{~kW}$. It was determined, as a result, that their maximum size (length up to $500 \mu \mathrm{m}$ ) and amount (up to $10 \%$ ) is observed in the case of $v=45 \mathrm{~m} / \mathrm{h}$, whereas length of crack propagation somewhat reduces and makes $50-450 \mu \mathrm{m}$ at their amount up to $2 \%$ (Figure $6, a$ ) with $24 \mathrm{~m} / \mathrm{h}$ minimum speed. It should be noted that content of chromium rises up to $20-26 \%$ in areas with microcracks, tungsten concentration at that makes around $2-5 \%$. Increase of chromium content (Figure $6, b$ ) is sufficiently well observed at a map of concentration distribution of chemical elements in a central zone of the alloyed layer in the presence of crack. However, the microcracks are virtually absent under conditions of average speeds $(v=30 \mathrm{~m} / \mathrm{h})$ that indicates the optimum structural state of the alloyed layer from point of view of crack resistance.

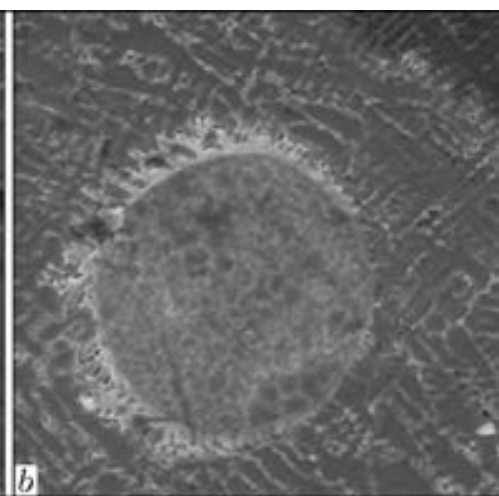

Figure 5. Microstructure of surface layer with $\mathrm{WC}-\mathrm{W}_{2} \mathrm{C}$ inclusions in laser alloying $(a-\times 3100 ; b-\times 1200)$ 


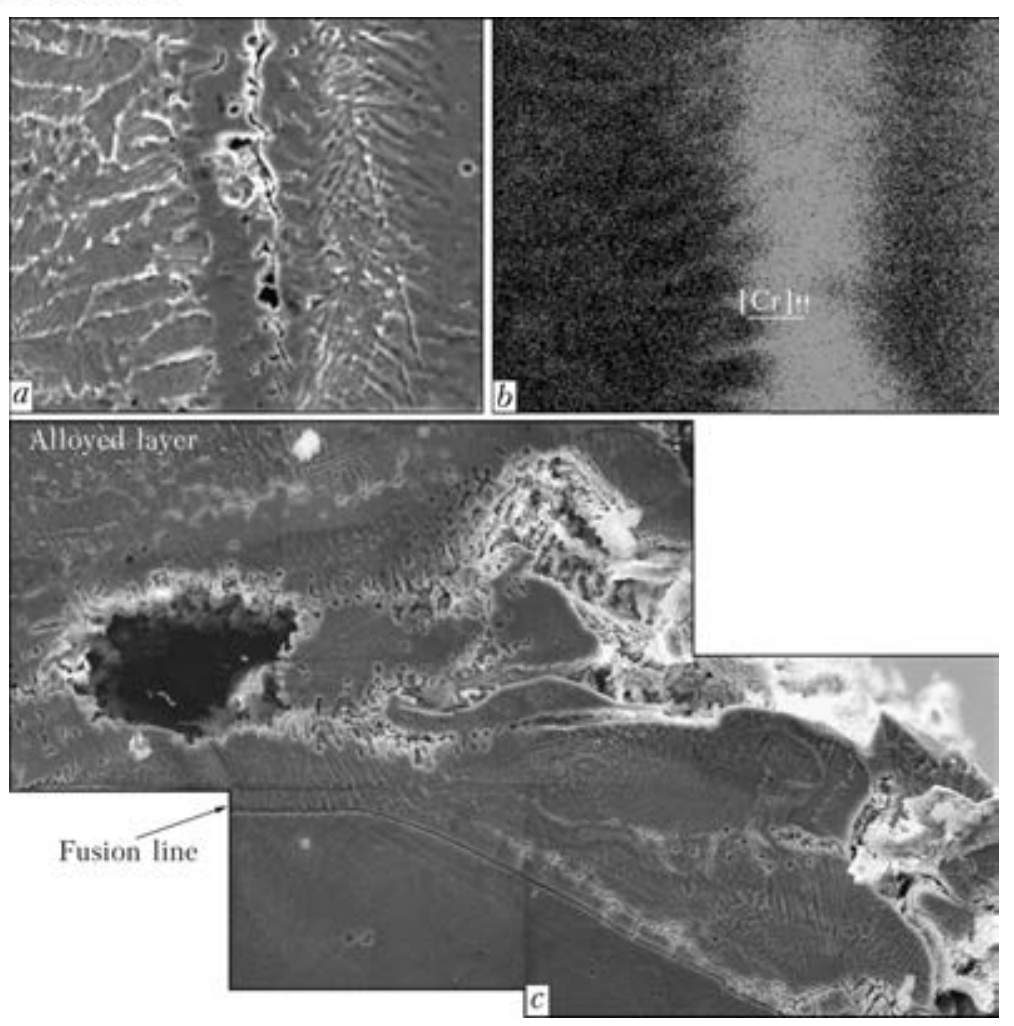

Figure 6. Microstructure of alloyed layer with microcrack in central zone $(a-\times 1500)$, distribution of chromium along given crack $(b-\times 1500)$, and microstructure of alloyed layer with microcrack in area of fusion line $(c-\times 1200)$ in the case of application of laser treatment method

Increase of irradiation power to $4.4 \mathrm{~kW}$ promotes reduction of thickness of the alloyed layer from 2.70 to $1.50 \mathrm{~mm}$ with rise of treatment speed from 24 to $42 \mathrm{~m} / \mathrm{h}$. Metal of the alloyed layer has defined crystalline structure (as in the case of alloying at $P=3.5 \mathrm{~kW}$ ), having large extension (elongation) at average shape coefficient $\kappa=10$ for all cases of treatment speeds. This is approximately 2 times higher in comparison with the structural variations observed in alloying using $3.5 \mathrm{~kW}$ power.

Reduction of hardness of the microalloyed layer on average to $26 \%$ is also observed depending on increase of alloying speed at $P=4.4 \mathrm{~kW}$. At that, for all cases of applied alloying speeds, the microhardness gradient $\Delta H V$ in the fusion line (namely, $\Delta H V$ between alloyed layer and base metal) reduces with increase of speed of laser alloying from 24 to $36 \mathrm{~m} / \mathrm{h}$. However, rapid rise of the microhardness gradient is observed in the case of maximum speed $42 \mathrm{~m} / \mathrm{h}$.

Investigation of concentration variations along the transfer zone, the size of which reduces from 60 to $40 \mu \mathrm{m}$ for $P=4.4 \mathrm{~kW}$ (at speed changing from 24 to $42 \mathrm{~m} / \mathrm{h}$ ), showed insignificant variations of iron concentration in the alloyed layer $\rightarrow$ fusion zone $\rightarrow$ base metal transfer. Distribution of chromium concentration varies from 8 to $13 \%$ in the alloyed layer with rise of speed, with gradual reduction, approximately, to $8 \%$ in the transfer zone in approaching to the fusion line. Tungsten distribution also changes from 2 to $5 \%$ in the alloyed layer in the case of rise of laser alloying speed, and its concentration in the transfer zone gradually reduces, approximately, 2 times at transfer to the fusion line.

As for the presence of cracks and factors, related with crack formation, then the investigations determined presence of microcracks (in all investigated areas), length of which reduce from 500 to $40 \mu \mathrm{m}$ with increase of the treatment speed (see Figure 6) in all specimens, obtained with $P=4.4 \mathrm{~kW}$. At that, the zone of crack formation exhibits a rise of chromium concentration from 17 to $26 \%$ with increase of alloying speed, and content of tungsten remains at the level of 1.0$4.5 \%$ in all modes.

Laser-microplasma alloying. The following was determined in relation to structural-phase and concentration variations, and conditions of crack formation in the surfaces of 38KhN3MFA steel, treated by combined laser-microplasma source using constant $P=3 \mathrm{~kW}$, but at different speed (from 30 to $45 \mathrm{~m} / \mathrm{h}$ ) in deposition of different number of paths.

Thickness of the alloyed layers, obtained by method of laser-microplasma alloying, reduces from 1.75 to $1.58 \mathrm{~mm}$ with rise of alloying speed. Metal of alloyed surface layer, similar to laser 


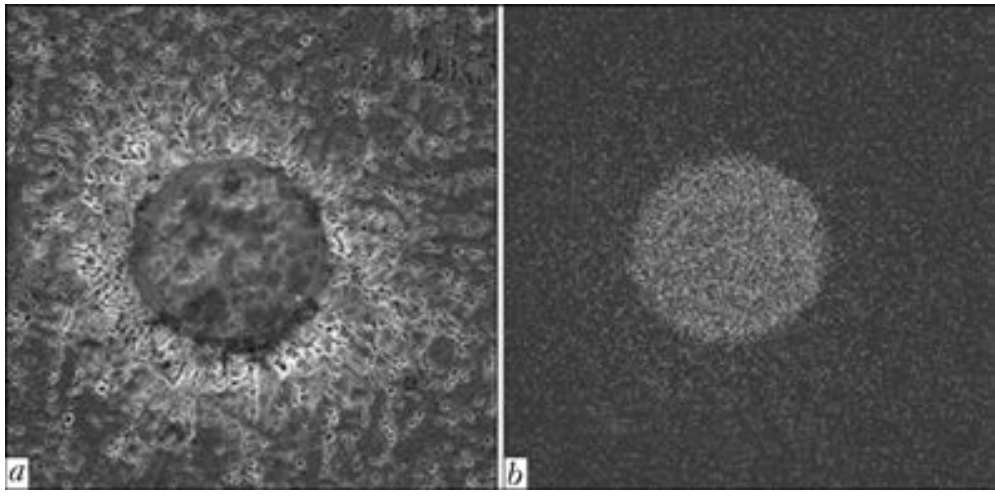

Figure 7. Microstructure $(\times 1010)$ of surface layer with $\mathrm{WC}-\mathrm{W}_{2} \mathrm{C}$ inclusions in laser-microplasma alloying: $a-$ appearance of inclusions; $b-$ maps of tungsten distribution in these inclusions

treatment, has defined crystalline structure, but differ by more equiaxed and fine grain crystalline particles (see Figure $3, b$ ) and coefficient of their shape rises from 4 at $v=30 \mathrm{~m} / \mathrm{h}$ to 8 at $45 \mathrm{~m} / \mathrm{h}$.

It should be noted that width of HAZ area, forming in the fusion line from $38 \mathrm{KhN} 3 \mathrm{MFA}$ steel side, reduces from 1.65 to $1.25 \mathrm{~mm}$ with increase of alloying speed in contrast to laser treatment, where this area rises on the contrary. HAZ metal microstructure, as in laser treatment, is mainly martensite, but characterizes by $20-30 \%$ reduction of microhardness under conditions of rise of alloying speed and deposition of several overlap paths.

Investigations of concentration variations showed insignificant change on iron in all studied areas (from outer surface to base metal). At that, distribution of chromium in the alloyed layer changes from 6 to $18 \%$ depending on increase of alloying speed and number of deposited paths, and tungsten distribution in the alloyed layer varies from $2-3$ to $8 \%$, respectively.

Alloyed layer, obtained by laser-microplasma alloying method, at all alloying speeds (as well as in laser alloying) demonstrates presence of inclusions, the volume fraction of which rises from 1 to $10 \%$ with increase of alloying speed from 30 to $45 \mathrm{~m} / \mathrm{h}$, respectively. These inclusions

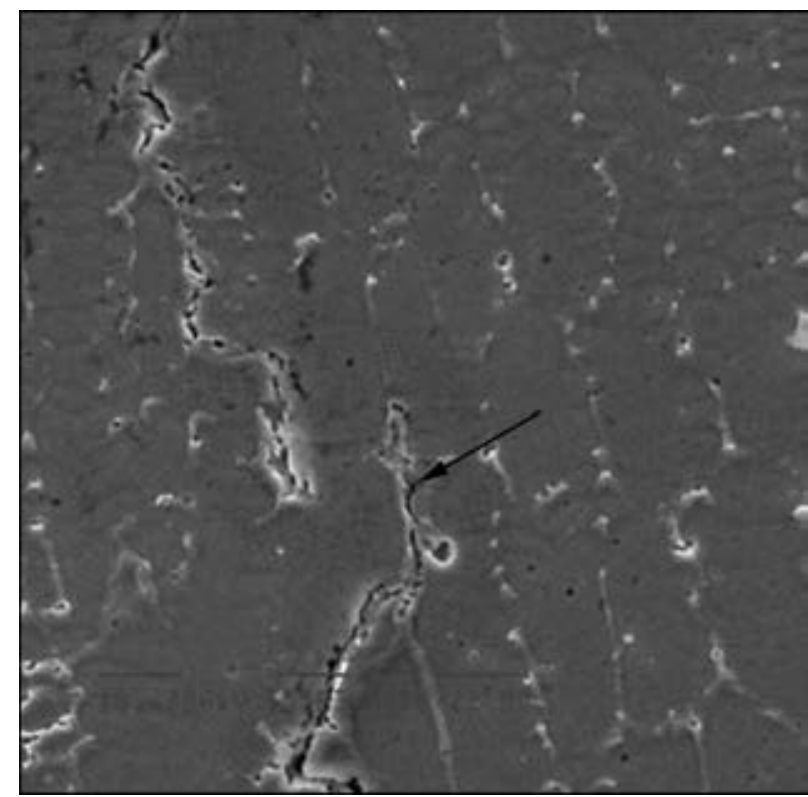

Figure 8. Microstructure $(\times 1550)$ of surface layer with microcrack after laser-microplasma alloying

have $50-230 \mu \mathrm{m}$ size and consist mainly of $\mathrm{WC}-$ $\mathrm{W}_{2} \mathrm{C}$ with tungsten content on average $97 \%$ (Figure 7).

The investigation also determined presence of microcracks (volume fraction $V_{\text {cr }}$ from 3 to $30 \%$ ) under conditions of laser-microplasma alloying. However, in contract to modes of laser alloying,

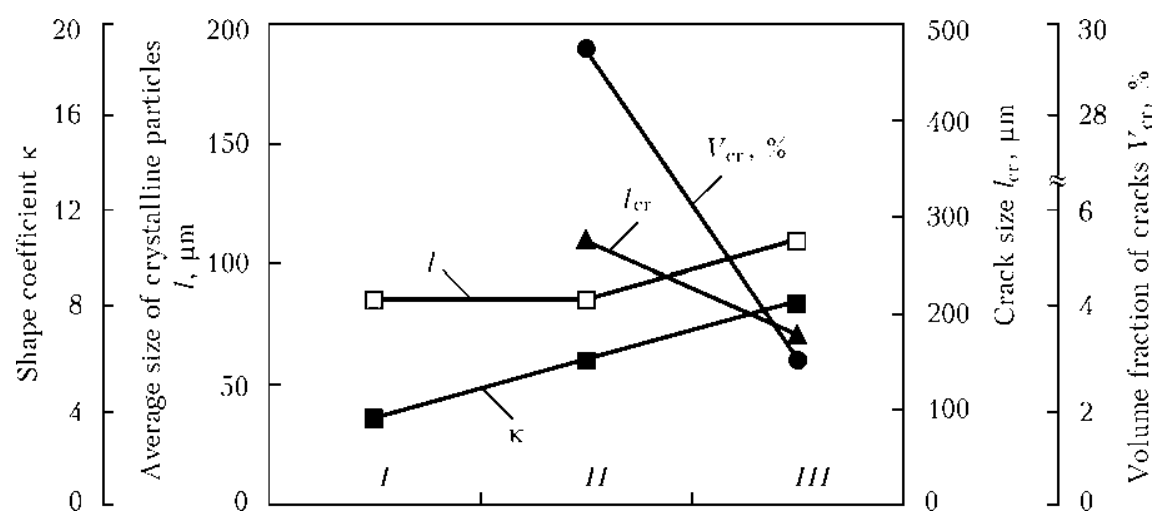

Figure 9. Comparative diagram of structural parameters and microcracks in alloyed layer after laser-microplasma treatment: $I-P=3 \mathrm{~kW}, v=30 \mathrm{~m} / \mathrm{h}$, deposition of 1 path; $I I-P=3 \mathrm{~kW}, v=30 \mathrm{~m} / \mathrm{h}$, deposition of 4 paths; $I I I-P=$ $=3 \mathrm{~kW}, v=45 \mathrm{~m} / \mathrm{h}$, deposition of 3 paths 
such defects are observed only in the alloyed layer along crystalline particle boundaries (Figure 8), and they are virtually absent in the zone of fusion line, that indicate good cohesion of the alloyed layer with $38 \mathrm{KhN} 3 \mathrm{MFA}$ steel. Increase of chromium content to $12-20 \%$ is registered in the areas of crack formation. It should be specifically outlined that no microcracks are present $\left(\mathrm{Fi}^{-}\right.$ gure 9) in the case of laser-microplasma alloying with $v=30 \mathrm{~m} / \mathrm{h}$ (one path).

Thus, it was determined at present stage of investigation that the most optimum structural parameters of the alloyed layer are formed using $P=3.5 \mathrm{~kW}$, and $v=30 \mathrm{~m} / \mathrm{h}$ mode for laser alloying, and $P=3 \mathrm{~kW}, v=30 \mathrm{~m} / \mathrm{h}$ for lasermicroplasma alloying (deposition of one path).

\section{Conclusions}

1. Susceptibility to crack formation of specimens from 38KhN3MFA steel in laser and laser-microplasma alloying is caused, first of all, by structural (size of crystalline particles, coefficient of their shape) and concentration variations, related with redistribution of elements, in particular, chromium, that results in formation of sharp grain boundary concentration gradients.
2. Absence of microcracks in the fusion zone during laser-microplasma method allows making a conclusion about its perspective for parts manufactured from 38KhN3MFA steel.

3. It was determined, at present stage of investigation, that the most optimum structural parameters of the alloyed layer are formed using $P=3.5 \mathrm{~kW}$ and $v=30 \mathrm{~m} / \mathrm{h}$ mode for laser alloying, and $P=3 \mathrm{~kW}, v=30 \mathrm{~m} / \mathrm{h}$ for lasermicroplasma alloying (one path).

1. Isaev, G.P. (2002) Laser-ion alloying of metals and alloys. Vestnik KamchatGTU, 1, 160-164.

2. Lakhtin, Yu.M., Leontieva, V.P. (1980) Materials science: Manual for institutions of higher education. Moscow: Mashinostroenie.

3. Petrova, L.G. (2010) Practical application of models of chemical-heat treatment for development of surface strengthening technologies. Vestnik KharkovNADI, 51, 26-34.

4. Grigoriants, A.G. (1989) Principles of laser treatment of materials. Moscow: Mashinostroenie.

5. Grigoriants, A.G., Shiganov, I.N., Misyurov, A.I. (2006) Technological processes of laser treatment: Manual for institutions of higher education. Moscow: N.E. Bauman MGTU.

6. Grabin, V.F. (1982) Metals science of fusion welding. Kiev: Naukova Dumka.

Received 30.09.2013 